\title{
INVENTANDO UM TEMPO
}

CREATING A TIME

INVENTAR UN TIEMPO

Marcus André Vieira*

Resenha do livro: Barros, R. (2012). Compulsóes e obsessóes - uma neurose de futuro. Rio de Janeiro: Civilização Brasileira, 2012. 125 pp.

O livro de Romildo do Rêgo Barros, Uma neurose de futuro, é um daqueles raros textos multiuso. Em cerca de cento e vinte páginas, ele é ao menos três-em-um: uma introdução à clínica psicanalítica, um manual para o tratamento de obsessóes e compulsões e uma reflexão sobre o lugar da psicanálise na cultura. Cada um destes livros tem sua originalidade própria. Como introdução, ele é redigido por um psicanalista que sabe escrever com a simplicidade e clareza de quem vive o que diz, mas sem concessóes à vulgarização (algo raro quando tantos hoje ensinam os conceitos da psicanálise mais do que exploram os meandros de sua clínica). Como manual da neurose obsessiva, ele nos conduz a descobrir o quanto as sutilezas de uma vida só ganham leitura quando a elas acrescentamos algo nosso, exatamente o que o obsessivo evita a todo custo. Como reflexão sobre a psicanálise, proporciona um olhar panorâmico sobre o século vinte, de Freud a Lacan, mas ao mesmo tempo o de uma psicanálise que olha para si mesma e se reinventa no século vinte e um.

Um quarto livro, porém, me interessa destacar: o ensaio sobre um modo muito especial de viver o tempo, que se descobre a partir do trabalho de Freud com a neurose obsessiva. É desse ultimo que tratarei aqui, pois ilumina a atualidade dos outros que compóem o livro de Romildo.

Nele, aprendemos como Freud incide, na análise de Ernst Länzer, nosso Homem dos Ratos, no contrapé da manobra que o ocupa incessantemente, a de deslocar a ênfase do detalhe para o aspecto panorâmico, ou do vigor do instante à contemplativa eternidade.

Não é raro vivermos o desejo desse deslocamento, exercitado sem descanso pelo obsessivo, de nos alçarmos a um belvedere de nós mesmos, de escaparmos da

* Pontifícia Universidade Católica do Rio de Janeiro, Rio de Janeiro, RJ, Brasil. 
prisão dos dias para contemplar a própria história de fora, como um todo. Uma análise parece ter essa pretensão, mas apenas parece. Ao contrário, ela faz valer o singular de um desejo como tal, sem varrê-lo para debaixo do tapete do universal. É exatamente o que o livro demonstra a partir do modo como uma análise lida com a estratégia obsessiva.

Muita coisa está em jogo. Romildo reúne tanto o nascimento da psicanálise quanto a presença da neurose obsessiva na cultura, assim como o tratamento dado por Freud a essa neurose, tudo em um mesmo momento. A psicanalise seria filha de uma mutação na cultura que igualmente teria dado origem à neurose. Em seus termos: "Surgiu a partir dos séculos XVII e XVIII uma nova forma de esperança, diferente da religiosa, foi ela que deu lugar à neurose e a Freud" (Barros, p. 94).

Uma nova forma de esperança assinala a passagem da prevalência no campo da cultura de um Outro que tudo sabe, Deus, por exemplo, a um Outro ao qual falta saber. É o que torna possível a psicanálise, sustentada na possibilidade de uma busca da verdade em nós mesmos, que só nós possuímos um saber singular. A neurose é uma forma de viver esta esperança, fazendo, porém, com que a verdade permaneça sempre encoberta, para que se possa seguir buscando-a eternamente (Barros, p. 74).

O ensaio sobre essa nova forma de esperança, nova forma de relação com o tempo, se distribui ao longo de todo o texto. Mesmo em sua vertente de manual clínico, o livro aborda esse tema, mas, ao mesmo tempo, apresentando no detalhe a análise de Ernst com Freud, fornece elementos de resposta fundamentais para as seguintes questóes: o que é uma análise? Quais, nela, a função e lugar do analista? O que é uma neurose obsessiva? Como lidar com ela em análise? Na pena de Romildo, Ernst Länzer sai da tela, apresenta-se vivo e entre nós, assim como Freud, o que materializa bem concretamente o surgimento da nova forma de esperança, na clínica, no modo como Ernst toma posição com relação àquilo que falta no saber e lida com o pai (e com o analista) a partir disso.

Para Ernst Länzer, Freud e o próprio dispositivo analítico funcionaram como garantia de que há um sentido escondido (Barros, p. 116), de modo a que ele pudesse ser materializado em sua subversão para com o sentido comum.

É o que demonstra de modo direto Romildo ao aproximar o pensamento que atormenta Ernst do silogismo aristotélico mais básico nele incluindo, porém, um "abismo" da seguinte forma: "Se eu casar com a dama... a meu pai ocorrerá algum infortúnio" (Barros, p. 39). "O mérito de Freud foi perceber que nesse abismo [entre uma afirmação e outra] há uma afirmação escondida" - algo como "segundo meu desejo", o desejo de morte de Ernst, veiculado nas explosóes de raiva que tivera contra seu pai no passado. 
"O método criado por Freud teve por base inicial a introdução de um terceiro termo que torna possível a leitura do sintoma" (Barros, p. 100) em ruptura com o sentido normal. Normalmente as pessoas se entendem sem sentido oculto, o terceiro termo é "uma quebra com relação à alteridade (comum) e introdução de uma nova alteridade" (Barros, p. 100) - a alteridade dessa verdade oculta em nós mesmos, desconhecida de Deus ou do Pai, que Freud chamará inconsciente.

Neurose obsessiva é o nome dado ao movimento de encontrar a peça que falta para completar o quebra-cabeça exclusivamente para que tudo fique em seu lugar, imóvel. Basta que tudo se dê como uma cirurgia em que o vivo, aquilo que perturba a conclusão do quebra-cabeça por reconfigurá-lo a cada esquina, esteja como o corpo sob anestesia, em coma, fora de cena. Mas, Freud, por outro lado, propóe que se tome cada peça encontrada exatamente como aquela que reconfigura o quadro, descompleta-o e o torna, assim, sempre mutante, vivo.

Isso se demonstra não apenas no espaço, com uma frase oculta, mas também no tempo, pois a esperança de Ernst é igualmente um novo modo de viver o tempo e a introdução do terceiro termo a forma freudiana de lidar com essa esperança. Passamos, de Aristóteles à modernidade, de um tempo eterno das órbitas celestes em permanente rotação estática sobre si mesmas a um tempo que corre, escapa, uma eternidade do infinito, sempre além. Contrapondo-se a essa nova forma de eternidade, a de um eterno escoar dos grãos da ampulheta, Freud, diz Romildo, introduz "um tempo que não existia: um passado que impóe, ou aponta, para o futuro, ou que contém o futuro" (Barros, p. 63). O tempo de Freud é o tempo em que um acontecimento singular e contingente trará nova leitura a uma existência, ganhará lugar no universal.

Não é o que ocorre quando a célebre explosão de raiva de Ernst o insere em uma nova possibilidade de existência, tornando impossível, dali por diante, sua identificação com o filho modelo? Nada mais será como antes, o que justifica que Romildo aproxime o tempo de Freud ao tempo do ato.

É exatamente contra esse tempo que se estrutura o obsessivo. "A procrastinação é uma forma de inventar um futuro imune à contingência” (Barros, p. 57). Já a neurose "é, para Freud, sucedânea de um ato" (Barros, p. 56). Por isso, o ato compulsivo, será descrito como uma caricatura - uma caricatura do ato, dirá Romildo com Lacan (Barros, p. 50).

Mas Uma neurose de futuro contém ainda uma reviravolta. $\mathrm{O}$ ensaio sobre essa enorme mutação do Outro que deu origem tanto à psicanálise quanto à neurose não poderia se concluir sem interrogar-se sobre uma nova mutação, que parece estar em curso. De fato, a forma de esperança que deu origem tanto à neurose quanto à psicanálise parece estar se eclipsando em prol de outro modo 
de viver o saber e o gozo. Romildo nos mostra como a partir da compulsão podemos interrogar essa virada e sobre o lugar, nela, da psicanálise. Segundo ele, está havendo um declínio do conflito, ou melhor, "da própria ideia do conflito como princípio de explicação" (Barros, p. 99). Não há mais lugar para vacilação e dúvida sobre como gozar, pois o gozo passou de proibido, gerando a ambiguidade de sua obtenção apenas na transgressão, a disponível. E, se o gozo é possível, ele deve ser atingido e, assim sendo, obrigatório. $\mathrm{E}$ ai do sujeito se não souber como. Neste sentido, em vez de dúvida e culpa vivemos uma exigência generalizada de gozo. "Uma nova forma de vergonha surge no horizonte de nossa época, que se refere não ao que fizemos, mas sobretudo ao que deixamos de fazer" (Barros, p. 104). Ou ainda, citando Jacques-Alain Miller: "Estamos num ponto em que o discurso dominante determina que não se tenha mais vergonha de seu gozo [...] de seu desejo sim, mas não de seu gozo" (Barros, p. 102).

No lugar de um Outro que sabia a verdade surgiu aquele a quem faltava saber. O de hoje lida com o real de outro modo. Continua faltando-lhe saber, mas ele preenche essa falta calculando incessantemente as probabilidades de acerto e de erro de cada escolha. O Outro de nossos dias não sabe $o$ que é, mas calcula a todo instante $o$ que pode ser - como por exemplo o risco de um câncer de mama levando à decisão de cirurgia preventiva ou de uma doença degenerativa. Diante da onipresença do cálculo do risco, o tempo, que passara de eterno a infinito, de circular a fugitivo, agora é acelerado - não por prosseguir ao infinito, mas por se comprimir em um presente permanente. Se o tempo que escapa foi o de Freud e Lacan, como fazer análise hoje, em que estamos no tempo da decisão e do resultado direto e imediato?

Nós estaríamos hoje como Leonard Shelby, o personagem do filme Amnésia comentado por Romildo na seção "A neurose obsessiva na era dos TOCs". Shelby, a partir de um acontecimento traumático perde a memória, só retém cerca de dez minutos e se torna alguém "todo consciência" (Barros, p. 112), "a predominância da consciência sobre a memória torna sua vida um eterno presente" e ele passa a ter "seu futuro limitado a um imperativo [de vingar o pretenso assassinato de sua mulher]: cumprir um mandado esse ou aquele" (Barros, p. 113).

Romildo preserva o lugar da psicanálise ao nos demonstrar como ela é a invenção de outro tempo, dentro do tempo que escapa ou do tempo que se achatou. Aquilo de que alguém se lembra, escreve ele a partir de uma definição de Kierkegaard, é uma "retomada para trás", enquanto que a lembrança em uma análise traz uma "retomada para frente" (p. 60). "A reminiscência (em análise) tem um fundo de futuro" (Barros, p. 61). Uma análise é a possibilidade de trazermos um passado que recria nosso caminho. 
Que esse livro, o primeiro texto, neste formato de alguém cujo estilo já enriquece a comunidade psicanalítica há vários anos através de seu ensino e de um sem número de artigos, inaugure uma série. Aposto que ela nos trará novidades sobre os desdobramentos atuais da neurose.

Esperando os próximos, deixo o futuro leitor com mais algumas evidências do talento de Romildo, agora como autor de fórmulas agudas (trechos do livro):

O inconsciente freudiano é o inconsciente que somente existe enquanto trabalha. (p. 62); Para Freud a cultura somente existe se diz "não" a certo gozo (p. 87); A culpa de alguma forma está (sempre) ligada a uma dívida que mantemos com a alteridade (p. 97); De alguma forma e em algum momento todo mundo quer que alguma coisa [de ruim] aconteça com o pai, amando-o ou não (p. 83); A crise, quanto à igualdade, é devido à dificuldade em se situar a exceção a partir da qual a igualdade é possível (p. 100); A neurose obsessiva é um sucedâneo privado da religiáo (p. 69); Se a obediência do sujeito é levada longe demais, nos ensina Carlitos, torna-se algo comparável a um tique nervoso que a rigor, não tem sujeito (p. 77); Os sentimentos humanos não são simples, mas pelo contrário, constituem sínteses instáveis (p. 29); O bom parceiro do obsessivo, confiável e suficientemente estável, é aquele que sobreviveu a seu ódio (p. 37); O Outro do obsessivo pode e deve existir, ele não pode é desejar (p. 74); É uma ilusão, nada mais, achar que o acréscimo de sentido transforma o sujeito (p. 45); a interpretação analítica acarreta tanto uma produção de sentido quanto seu rompimento ao situar seu limite (p. 44): um mito é um relato que representa um salto por cima de uma impossibilidade (p. 88).

Recebido em 30 de agosto de 2013 Aceito para publicação em 16 de outubro de 2013 